\title{
Characterization of Solvent-Treated PEDOT:PSS Thin Films with Enhanced Conductivities
}

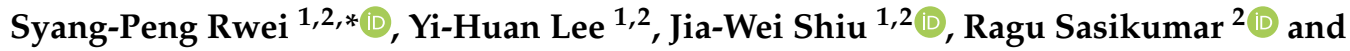 \\ Uin-Ting Shyr ${ }^{1,2}$ \\ 1 Institute of Organic and Polymeric Materials, National Taipei University of Technology, Taipei 10608, \\ Taiwan; yihuanlee@mail.ntut.edu.tw (Y.-H.L.); hahaluckybowen@gmail.com (J.-W.S.); \\ alexilaiho0422@gmail.com (U.-T.S.) \\ 2 Research and Development Center for Smart Textile Technology, National Taipei University of Technology, \\ Taipei 10608, Taiwan; sasi.che2011@gmail.com \\ * Correspondence: f10714@ntut.edu.tw
}

Received: 11 December 2018; Accepted: 11 January 2019; Published: 14 January 2019

check for updates

\begin{abstract}
The conducting polymer of poly(3,4-ethylenedioxythiophene):poly(4-styrenesulfonate) (PEDOT:PSS) is one of the most important and intensively investigated organic conducting materials. The PEDOT:PSS water dispersions with various concentrations of poly (4-styrenesulfonic acid) solution (PSSAS) were synthesized by 3,4-ethylenedioxythiophene (EDOT) in the presence of water. The fabrication of the solvent-treated PEDOT:PSS films through spin coating and solvent treatment processes was achieved with a solvent of pure water mixed with acetone (or $\mathrm{MeOH}, \mathrm{EtOH}$ ) in a ratio of 50:50. Moreover, both the organic solvent and water have synergetic effects while the PSS and PEDOT-attached PSS segments will form a coil-like and a linear (or extended-coil) structure, respectively. That may induce a stacking of the linear and planar PEDOT-attached PSS segments, which favors the formation of a crystalline phase. Finally, the maximum electrical conductivity of the PEDOT:PSS thin films with solvent treatment was investigated by means of X-ray diffraction (XRD) patterns and scanning electron microscope (SEM) images. Furthermore, we aimed to explain the synergetic effects of phase separation of the PEDOT:PSS thin films by both the organic solvent and water.
\end{abstract}

Keywords: PEDOT:PSS thin film; conducting polymer; electrical conductivity; X-ray diffraction

\section{Introduction}

Currently, organic conducting polymers have attracted interest in electronics due to their light weight, low cost and solution processible manufacturability. Moreover, polythiophene derivatives are one of the most successful conducting polymers due to their environmental stability, thermal stability, excellent film-forming ability and transparency [1-3]. However, polythiophene derivatives, such as poly(3,4-ethylene dioxythiophene) (PEDOT), are difficult to solvate in any solvent when in the conductive state. However, excess poly(4-styrenesulfonate) (PSS) that can be dispersed in water with good stability has been added in order to solve this problem. Furthermore, the conducting polymer of poly(3,4-ethylenedioxythiophene):poly(4-styrenesulfonate) (PEDOT:PSS) is one of the most important and intensively investigated organic conducting materials. This has the advantages of excellent film-forming performance, flexibility, wet-process ability, transparency, thermal stability and high conductivity for applications, such as wearable electronics, flexible displays, touch panels, solar cells, smart sensors, antistatic coatings, solid electrolytic capacitors and organic LEDs [4-11]. In addition, PEDOT:PSS thin films can enhance high conductivity through different film-forming methods, such as an addition of organic solvents (e.g., dimethyl sulfoxide (DMSO), ethylene glycol (EG)) and 
ionic liquid, spin coating, drop casting and diluting filtration. Moreover, the electrical conductivity of optimized PEDOT:PSS films can reach up to 1000 and $4000 \mathrm{~S} / \mathrm{cm}$ by polar-solvent vapor annealing methods and post-treatment with sulfuric acid, respectively [12-18]. Above all, conductivity can be enhanced by the addition of a polar organic solvent with a high boiling point, such as DMSO or EG, but not by a pure organic solvent with a low boiling point, such as acetone, methanol (MeOH), ethanol (EtOH), iso-propyl alcohol (IPA), acetonitrile (ACN) or tetrahydrofuran (THF). Thus, the electrical conductivity of PEDOT:PSS thin films that are treated by a pure organic solvent with a low boiling point is between 0.4 and $14.8 \mathrm{~S} / \mathrm{m}$. On the other hand, the conductivity enhancement of the PEDOT:PSS thin films can be achieved with a co-solvent of water mixed with an organic solvent, such as acetone, $\mathrm{MeOH}, \mathrm{EtOH}, \mathrm{IPA}, \mathrm{ACN}$ or THF. Thus, the electrical conductivity of PEDOT:PSS films that are treated by a co-solvent is between 40.9 and $78.9 \mathrm{~S} / \mathrm{m}$. The enhancement of conductivity was attributed to the preferential solvation of the PEDOT and PSS chains with the co-solvents. Furthermore, the electrical conductivity can be as high as $700 \mathrm{~S} / \mathrm{cm}$ at the optimum composition ratio between the PEDOT and PSS $[19,20]$.

In this study, we synthesized conductive PEDOT:PSS dispersions with various PSS ratios through oxidative polymerization. The significant enhancement of the conductivity of PEDOT:PSS thin films through solvent treatments of the water mixed with an organic solvent, such as acetone, $\mathrm{MeOH}$ and $\mathrm{EtOH}$, are analyzed by means of X-ray diffraction (XRD) patterns and scanning electron microscope (SEM) images in order to explain the synergetic effects of phase separation of the PEDOT:PSS thin films by both the organic solvent and water.

\section{Experimental}

\subsection{Materials}

Quantities of 3,4-ethylenedioxythiophene (EDOT, 97\%), poly (4-styrenesulfonic acid) solution (PSSAS, $\left.M_{\mathrm{w}}: 75,000\right)$, Amberlyst ${ }^{\circledR} 15$ hydrogen as a cation exchange resin and Amberlyst ${ }^{\circledR}$ A26 hydroxide as an anion exchange resin were purchased from Sigma-Aldrich, Inc., Taipei, Taiwan. Iron(II) sulfate heptahydrate $\left(\mathrm{FeSO}_{4} \cdot 7 \mathrm{H}_{2} \mathrm{O}\right)$ as a catalyst, sodium persulfate $\left(\mathrm{Na}_{2} \mathrm{~S}_{2} \mathrm{O}_{8}\right)$ as an oxidation agent and hydrochloric acid $(\mathrm{HCl}, 37 \%)$ were purchased from Showa Chemical Industry Co., Ltd., Tokyo, Japan. Commercial PEDOT:PSS (ORGACON ICP1050) was purchased from Agfa Taiwan Co., Ltd., Taipei, Taiwan. All other chemicals, solvents and reagents used were of analytical grade. Deionized water (DI water) was used in all experiments.

\subsection{Fabrication of PEDOT:PSS Dispersions}

The PEDOT:PSS dispersions with various concentrations of PSSAS (2.4, 4.8 and 6.2\%) were synthesized by EDOT in the presence of $200 \mathrm{~mL}$ of water. First, PSSAS were mixed in $200 \mathrm{~mL}$ of water containing $0.98 \mathrm{wt} \%$ of $\mathrm{Na}_{2} \mathrm{~S}_{2} \mathrm{O}_{8}$ as an oxidation agent and $0.2 \mathrm{wt} \%$ of $\mathrm{FeSO}_{4} \cdot 7 \mathrm{H}_{2} \mathrm{O}$ as a catalyst under low pressure conditions with a motor pump at room temperature (RT) for $1 \mathrm{~h}$. After this, $305 \mu \mathrm{L}$ of $\mathrm{HCl}$ was mixed in water under low pressure conditions with a motor pump at $20^{\circ} \mathrm{C}$ for $30 \mathrm{~min}$ before $751 \mu \mathrm{L}$ of EDOT was added to water under a nitrogen atmosphere at $20^{\circ} \mathrm{C}$ for $24 \mathrm{~h}$. After polymerization, the resulting sodium, iron and sulfate ions were removed using the cation exchange (Amberlyst ${ }^{\circledR} 15$ ) and anion exchange (Amberlyst ${ }^{\circledR}$ A26) resins. The processes of the PEDOT:PSS water dispersions and the solvent-treated PEDOT:PSS thin films are shown in Scheme 1.

\subsection{Fabrication of Untreated PEDOT:PSS Thin Films}

The untreated PEDOT:PSS thin films were fabricated by spin coating. PEDOT:PSS dispersions were dropped onto a glass substrate at $350 \mathrm{rpm}$ for $90 \mathrm{~s}$. Thermal annealing was conducted under an air atmosphere at $110^{\circ} \mathrm{C}$ for 30 min to obtain untreated PEDOT:PSS thin films (film A, B and C, for 2.4, 4.8 and $6.2 \%$ PSSAS, respectively) (Scheme 1). 


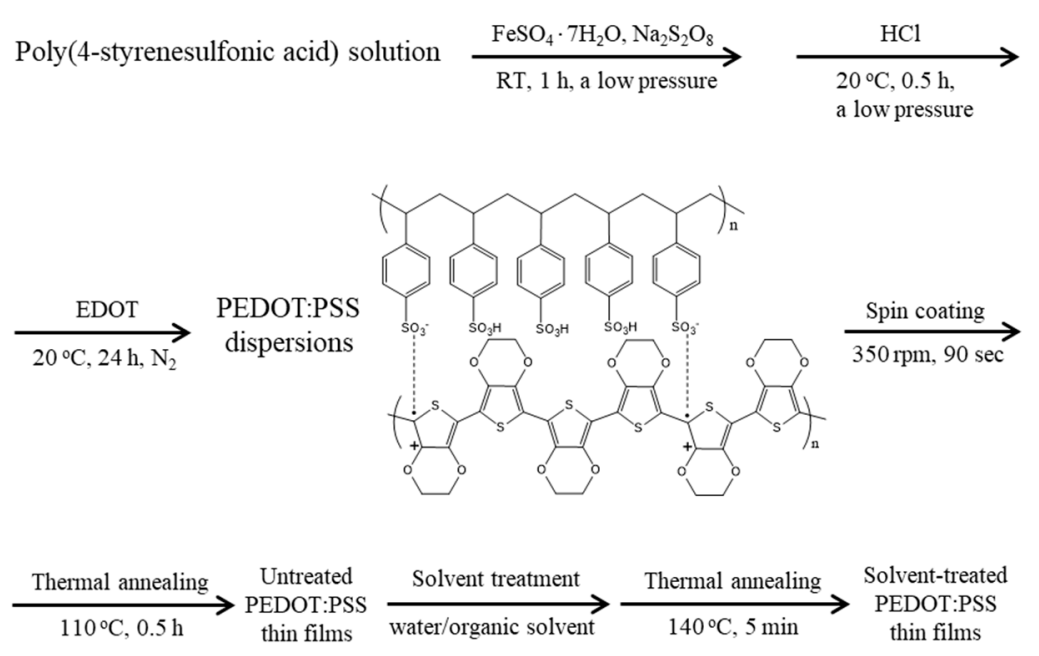

Scheme 1. Processes of the poly(3,4-ethylenedioxythiophene):poly(4-styrenesulfonate) (PEDOT:PSS) water dispersions, untreated PEDOT:PSS thin films and the solvent-treated PEDOT:PSS thin films.

\subsection{Fabrication of Solvent-Treated PEDOT:PSS Thin Films}

Pure water was mixed with acetone $(\mathrm{MeOH}$ or $\mathrm{EtOH})$ in a ratio of 50:50 as the solvent for treating the PEDOT:PSS thin films. The solvent was dropped onto a untreated PEDOT:PSS thin film (A, B or C) before thermal annealing was conducted under an air atmosphere at $140{ }^{\circ} \mathrm{C}$ for $5 \mathrm{~min}$ to obtain solvent-treated PEDOT:PSS thin films (Scheme 1).

\subsection{Measurements}

X-ray diffraction (XRD) patterns were measured by Malvern Panalytical, Empyrean. Surface morphology was investigated by means of a scanning electron microscope (SEM, JEOL/JSM-7610F). Electrical conductivity of the PEDOT:PSS thin films was measured by a normal four-point method (Loresta-GP MCP-T600, Mitsubishi Chemical Analytech Co., Ltd., Kanagawa, Japan).

\section{Results and Discussion}

\subsection{XRD Measurements of the PEDOT:PSS Thin Films}

The X-ray patterns and fitting curves of the PEDOT:PSS thin films (film A, B and C for 2.4, 4.8 and $6.2 \%$ PSSAS, respectively), which were either untreated and prepared by spin coating and thermal annealing or solvent-treated and prepared by the solvent treatment and thermal annealing (as shown in Scheme 1), are shown in Figure 1. According to Figure 1, all of the peaks from the PEDOT:PSS thin films have angle positions at $2 \theta=18^{\circ}$ and $26^{\circ}$, which were contributed from PSS at $2 \theta=18^{\circ}$. As shown in Figure 2, the XRD pattern of the PSSAS powder revealed an obvious intensity of the angle position at $2 \theta=18^{\circ}$, which can be assigned to the (020) planes of the orthorhombic unit cell of PEDOT crystals at $2 \theta=26^{\circ}$ [21-23]. Moreover, all XRD spectra of the PEDOT:PSS thin films that were prepared with various concentrations of PSS were similar to the XRD spectrum of the commercial PEDOT:PSS as shown in Figure 2. In addition, the differences in the intensities of the angle positions at $2 \theta=18^{\circ}$ and $26^{\circ}$ in the XRD spectra of the PEDOT:PSS thin films were due to the differences in the various concentrations of the PSSAS and the solvent treatment with a solvent of pure water mixed with acetone $(\mathrm{MeOH}$ or EtOH) in a ratio of 50:50. Thus, in order to further examine this phenomenon, the XRD patterns of the PEDOT:PSS thin films were fitted as shown in Figure 1. The parameters of fitting at $2 \theta$ and intensity are summarized in Table 1 , with all conductivities and parameters determined as the average value obtained from at least three samples. In addition, the fitted value of $2 \theta$ ranged between $17.70^{\circ}$ and $18.99^{\circ}$ as a fitting for the angle position at $2 \theta=18^{\circ}$ of the XRD patterns of the PEDOT:PSS thin films. Furthermore, the fitted value of $2 \theta$ ranged between $24.25^{\circ}$ and $24.82^{\circ}$ as a fitting for the angle position at $2 \theta=26^{\circ}$. Furthermore, the fitted intensities of the fitting at $2 \theta=18^{\circ}$ 
were increased by increasing the concentration of PSSAS but we were interested in the fitted intensities of the fitting at $2 \theta=26^{\circ}$. In the untreated cases, the fitted intensities were decreased by increasing the concentration of the PSSAS. It is known that there is an excess amount of PSS in the PEDOT:PSS aqueous solution and PEDOT is surrounded by PSS in order to stabilize its dispersion in water. Moreover, PEDOT chains attach to a PSS chain through Coulombic attraction forces and can have a necklace-like structure [20], which has two conformations of PSS and PEDOT-attached PSS segments. In the case of PEDOT-attached PSS segments, which are screened by the positive charges on the PEDOT in order to reduce the Coulombic repulsions between the PSS anions [24], they have a coil-like structure and the PEDOT-attached PSS segments form blobs to draw the PEDOT away from water. On the other hand, the PSS segments also form a linear structure in order to reduce the Coulombic repulsions between the PSS anions. Furthermore, Coulombic repulsions occur between these PEDOT-attached PSS blobs that have PSS anions in the shell and thus, each blob tries to draw itself away from the others and all blobs are separated as far as possible (Scheme 2). Hence, in the untreated cases, the fitted intensities of the fitting at $2 \theta=26^{\circ}$ were decreased by increasing the concentration of the PSS, which results in lower crystallinity of the PEDOT chains [19] because each blob tries to draw itself away from the others as far as possible at higher concentrations of the PSS. In contrast, in the solvent-treated cases, the fitted intensities of the fitting at $2 \theta=26^{\circ}$ followed an order of film B ( $4.8 \%$ PSSAS) $>$ film C (6.2\% PSSAS) > film A (2.4\% PSSAS). Therefore, the optimal concentration of the PSSAS is between 4.8 and $6.2 \%$.
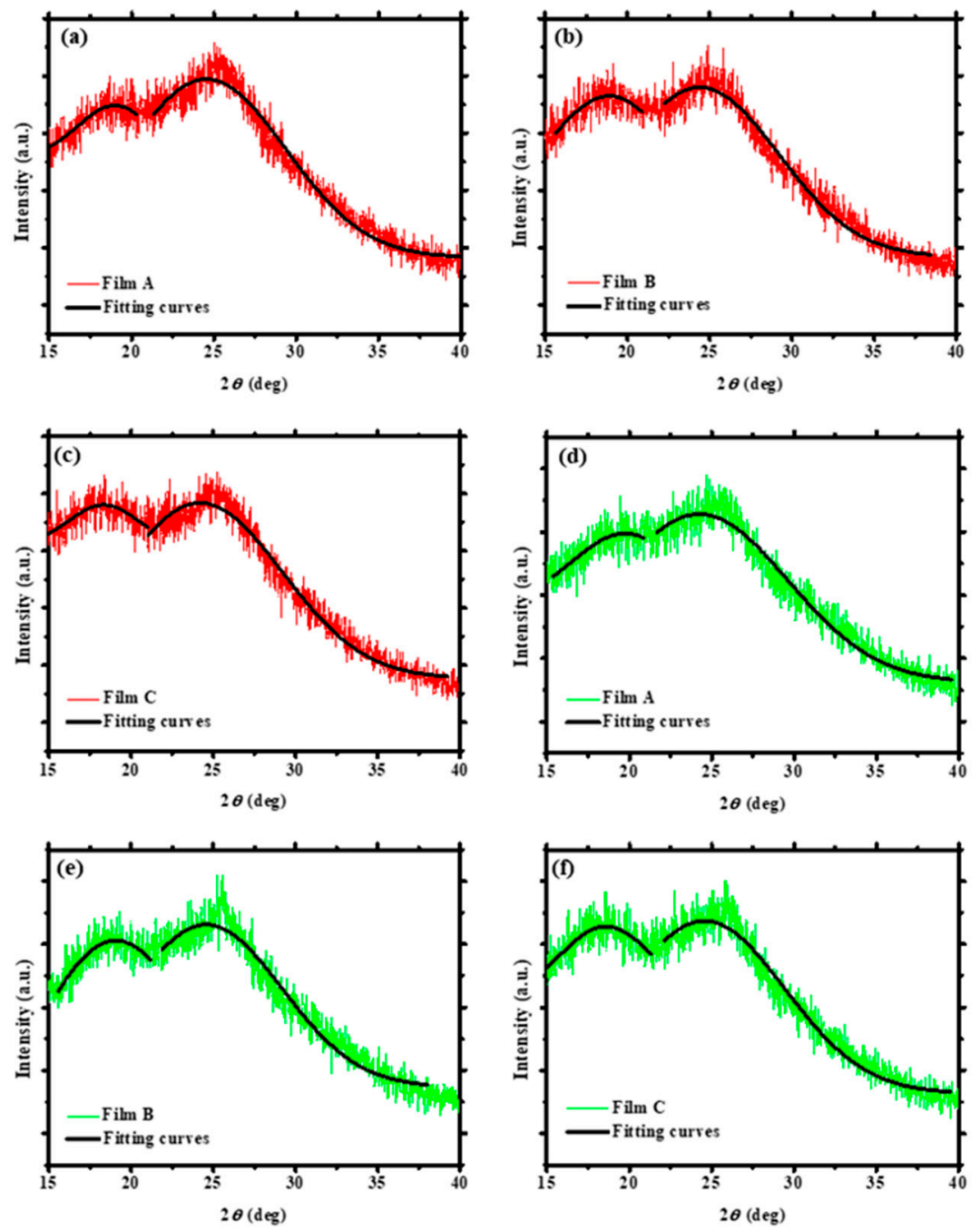

Figure 1. Cont. 

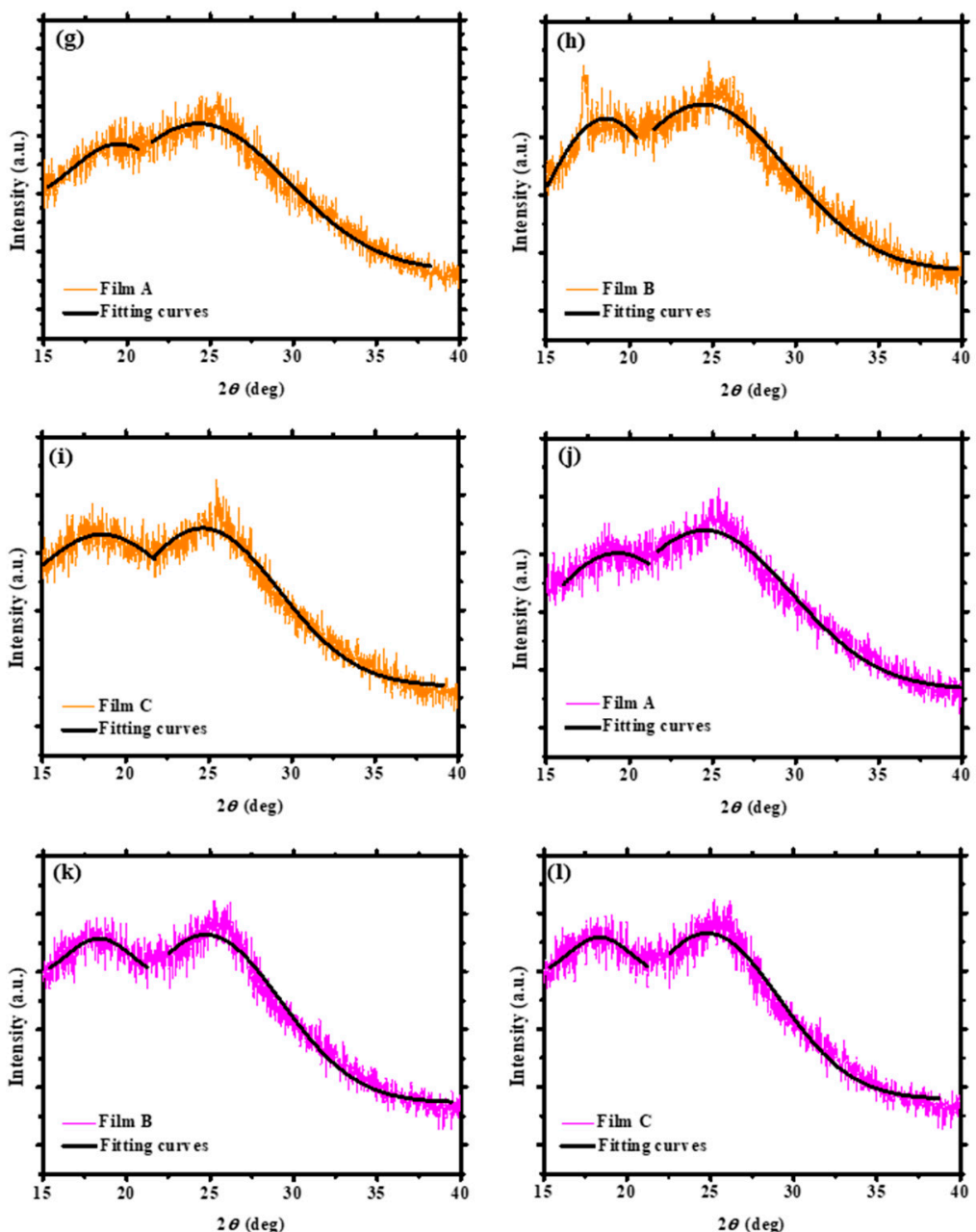

Figure 1. X-ray diffraction (XRD) spectra and fitting curves of the PEDOT:PSS thin film A (2.4\% PSSAS), B ( $4.8 \%$ PSSAS) and C (6.2\% PSSAS) without solvent treatments $(\mathbf{a}-\mathbf{c})$ and with solvent treatments of water/acetone $(\mathbf{d}-\mathbf{f})$, water/methanol $(\mathbf{g}-\mathbf{i})$ and water/ethanol $(\mathbf{j}-\mathbf{l})$.
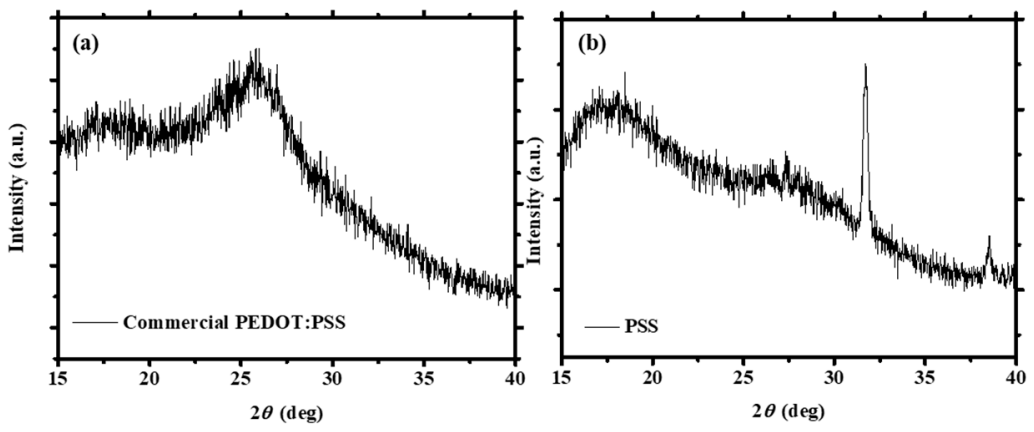

Figure 2. XRD spectra for the (a) commercial PEDOT:PSS and (b) PSSAS powder.

(a)

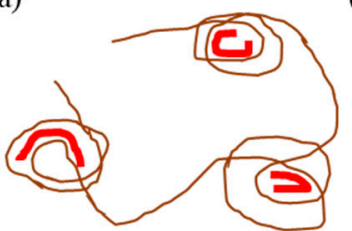

(b)

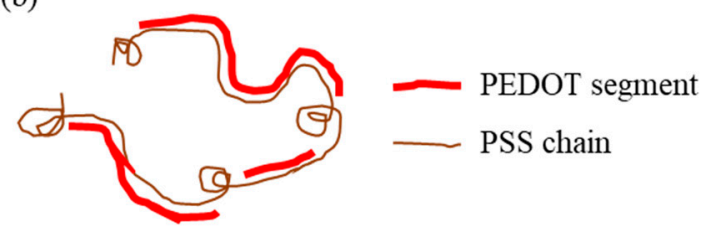

Scheme 2. Conformations of PEDOT:PSS: (a) untreated PEDOT:PSS and (b) solvent-treated PEDOT:PSS. 
Table 1. Conductivities and parameters of the fitting XRD spectra of the PEDOT:PSS thin film A (2.4\% PSSAS), B (4.8\% PSSAS) and C (6.2\% PSSAS) with solvent treatments of untreated, water/acetone, water $/ \mathrm{MeOH}$ and water $/ \mathrm{EtOH}$. All conductivities and parameters were determined as the average value of at least three samples.

\begin{tabular}{|c|c|c|c|c|}
\hline Solvent Treatment & Films & $\begin{array}{l}\text { Fitted } 2 \theta \\
\text { (Degree) }\end{array}$ & $\begin{array}{c}\text { Fitted Intensity } \\
\text { (Arbitrary Unit, a.u.) }\end{array}$ & $\begin{array}{l}\text { Conductivity } \\
(\mathrm{S} / \mathrm{cm})\end{array}$ \\
\hline \multirow{3}{*}{ Untreated } & Film A & $\begin{array}{l}18.51 \\
24.40\end{array}$ & $\begin{array}{l}527.42 \\
568.51\end{array}$ & 0.21 \\
\hline & Film B & $\begin{array}{l}18.55 \\
24.52\end{array}$ & $\begin{array}{l}539.14 \\
563.85\end{array}$ & 0.52 \\
\hline & Film C & $\begin{array}{l}18.46 \\
24.40\end{array}$ & $\begin{array}{l}544.76 \\
551.90\end{array}$ & 0.33 \\
\hline \multirow{3}{*}{ Water/acetone } & Film A & $\begin{array}{l}18.73 \\
24.25\end{array}$ & $\begin{array}{l}458.37 \\
503.96\end{array}$ & 19.89 \\
\hline & Film B & $\begin{array}{l}18.99 \\
24.56\end{array}$ & $\begin{array}{l}543.25 \\
570.61\end{array}$ & 35.33 \\
\hline & Film C & $\begin{array}{l}18.22 \\
24.60\end{array}$ & $\begin{array}{l}554.81 \\
546.81\end{array}$ & 30.43 \\
\hline \multirow{3}{*}{ Water/MeOH } & Film A & $\begin{array}{l}18.52 \\
24.28\end{array}$ & $\begin{array}{l}428.14 \\
467.49\end{array}$ & 14.99 \\
\hline & Film B & $\begin{array}{l}18.08 \\
24.65\end{array}$ & $\begin{array}{l}504.42 \\
577.62\end{array}$ & 40.51 \\
\hline & Film C & $\begin{array}{l}18.21 \\
24.82\end{array}$ & $\begin{array}{l}546.55 \\
566.53\end{array}$ & 32.37 \\
\hline \multirow{3}{*}{ Water/EtOH } & Film A & $\begin{array}{l}17.70 \\
24.80\end{array}$ & $\begin{array}{l}422.28 \\
511.06\end{array}$ & 25.99 \\
\hline & Film B & $\begin{array}{l}17.89 \\
24.51\end{array}$ & $\begin{array}{l}533.55 \\
583.45\end{array}$ & 46.07 \\
\hline & Film C & $\begin{array}{l}18.09 \\
24.82\end{array}$ & $\begin{array}{l}569.63 \\
578.58\end{array}$ & 34.35 \\
\hline
\end{tabular}

\subsection{Electrical Conductivity of the PEDOT:PSS Thin Films}

According to Table 1, the electrical conductivity of solvent-treated films was better than untreated films. These results indicate that the conductivity enhancement in the solvent-treated PEDOT:PSS thin films is different from that in the films that were treated with a polar solvent with a high boiling point, such as EG or DMSO, as the conductivity was greatly enhanced by directly adding a pure organic solvent into the PEDOT:PSS aqueous solution or treating a PEDOT:PSS thin film [24-27]. In general, organic solvents, such as $\mathrm{MeOH}$ and $\mathrm{EtOH}$, can be classified into an $\mathrm{OH}$ group and acetone can be classified into a non-OH group. However, there were no obvious differences in the conductivity enhancement between these two groups, which is consistent with our results. On the other hand, high conductivities are consistent with the high dielectric constants of the organic solvents, such as acetone. Moreover, the solvent treatment has effects from solvation [20], with an organic solvent, such as acetone that selectively solvates the PEDOT chains, and water that selectively solvates the PSS chains, which results in synergetic effects from both the organic solvent and water. Moreover, organic solvents mixed with water can reduce the dissociation of PSS into PSS anions and protons [28,29], which subsequently reduces the Coulombic repulsions among the PSS anions in the same polymer chain. In addition, the PSS and PEDOT-attached PSS segments will form a coil-like and a linear (or extended-coil) structure, respectively. Finally, the coil-like PSS segments can facilitate the phase separation of PSS chains from the PEDOT:PSS thin film (Scheme 2). Hence, in our case, acetone (MeOH or $\mathrm{EtOH}$ ) was mixed with water in a ratio of 50:50 and this mixture was used as a solvent for the treatment of PEDOT:PSS thin films, which resulted in better conductivities than untreated PEDOT:PSS thin films. Figure 3 shows the SEM images of the PEDOT:PSS thin films, which experience significant 
phase separation with the solvent treatment,. Furthermore, the linear (or extended-coil) structure of the PEDOT-attached PSS segment (Figure 3d-1) is shown compared to the structure of the segment with no treatment (Figure 3a-c). On the other hand, the conductivities of the PEDOT:PSS thin films with the solvent treatment have a trend of film B $>$ film $\mathrm{C}>$ film A and the trend is significantly consistent with the trend of the fitted intensities of the fitting at $2 \theta=26^{\circ}$. However, the untreated PEDOT:PSS thin films do not show the same trend. Thus, the trend depends on the solvent treatment, as shown in Table 1 and plotted in Figure 4, with intensities at fitting at $2 \theta=26^{\circ}$ and conductivities as functions of the PSSAS ratio for the PEDOT:PSS thin films. The changing intensities at fitting at $2 \theta=26^{\circ}$ were attributed to the synergetic effects from both the organic solvent and water. This can reduce the dissociation of PSS into PSS anions and protons, which subsequently reduces the Coulombic repulsions among the PSS anions in the same polymer chain. Thus, the PSS and PEDOT-attached PSS segments will form a coil-like and a linear (or extended-coil) structure, respectively. This may induce the stacking of the linear and planar PEDOT-attached PSS segments, which favors the formation of a crystalline phase [30], so that the XRD intensity increases with an increase in crystallinity. Finally, in our case, the best electrical conductivity of the PEDOT:PSS thin films with the solvent treatment depends on the best XRD intensity of fitting at $2 \theta=26^{\circ}$ of the film B, which is shown in Figure 4.
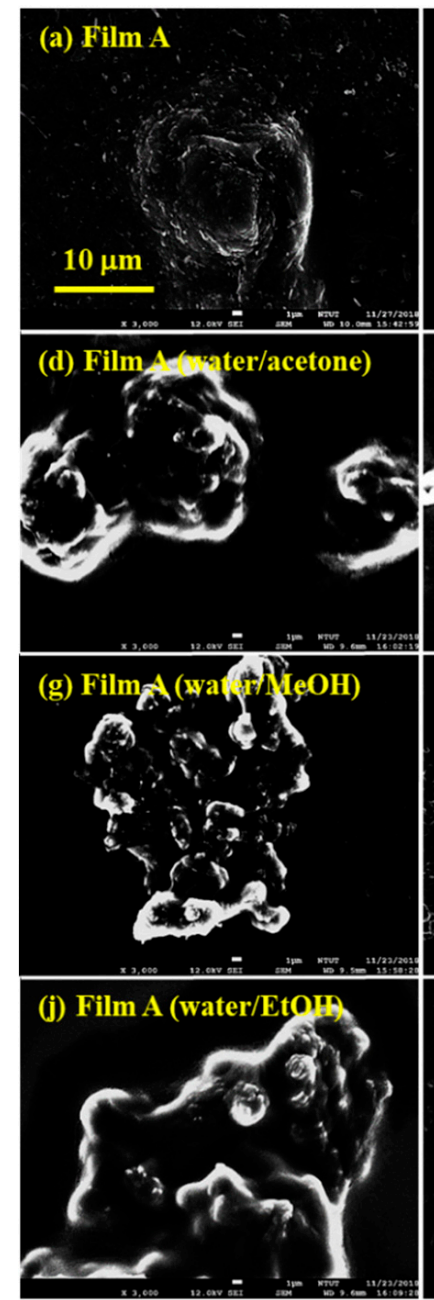
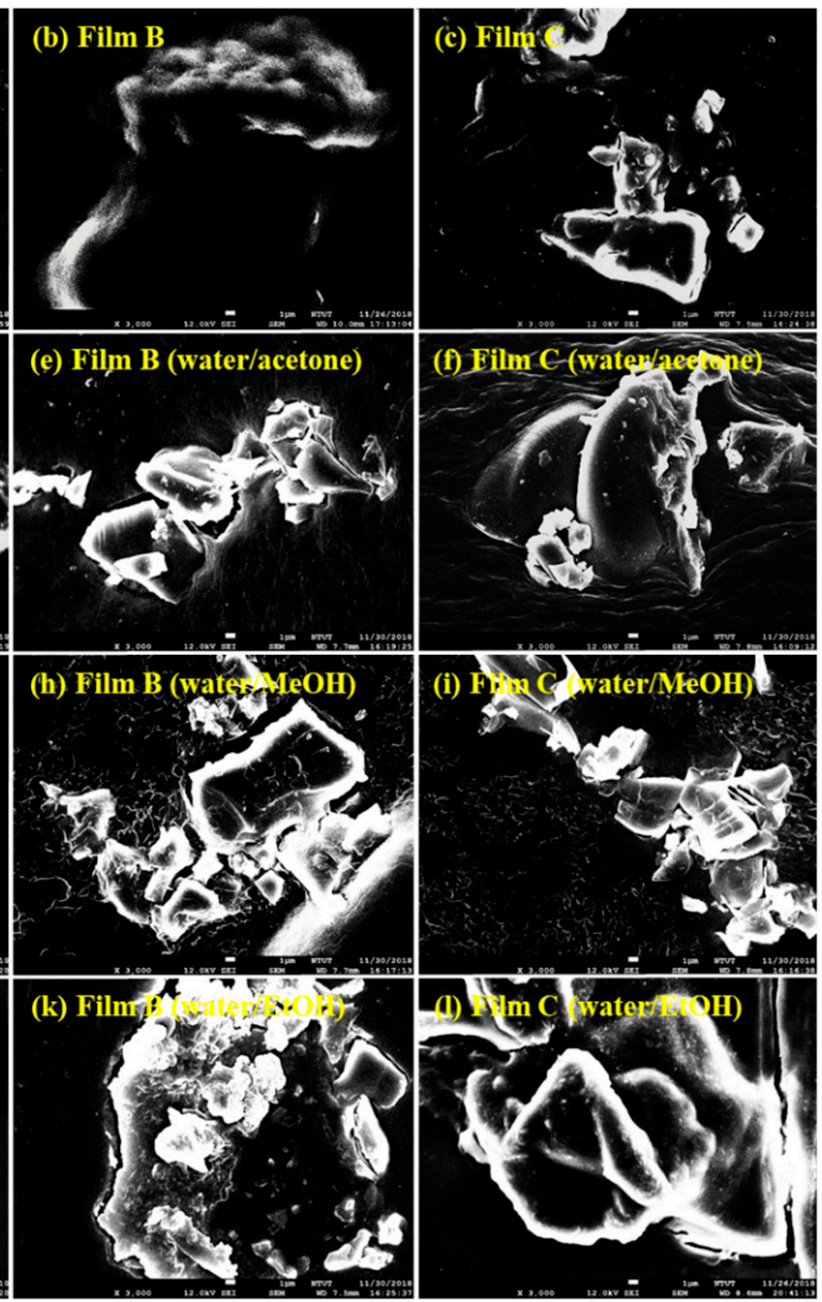
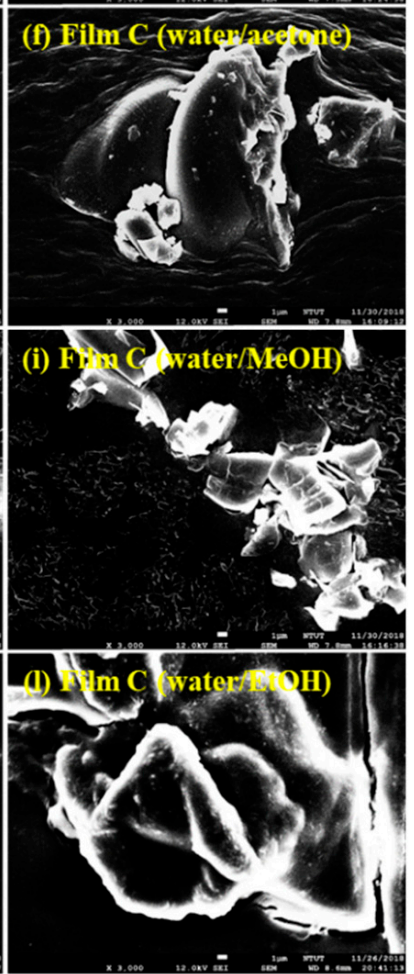

Figure 3. Scanning electron microscope (SEM) images of the PEDOT:PSS thin film A (2.4\% PSSAS), B (4.8\% PSSAS) and C (6.2\% PSSAS) without solvent treatments $(\mathbf{a}-\mathbf{c})$ and with solvent treatments of water/acetone $(\mathbf{d}-\mathbf{f})$, water/methanol $(\mathbf{g}-\mathbf{i})$ and water/ethanol $(\mathbf{j}-\mathbf{l})$. All the images use the same scale bar. 

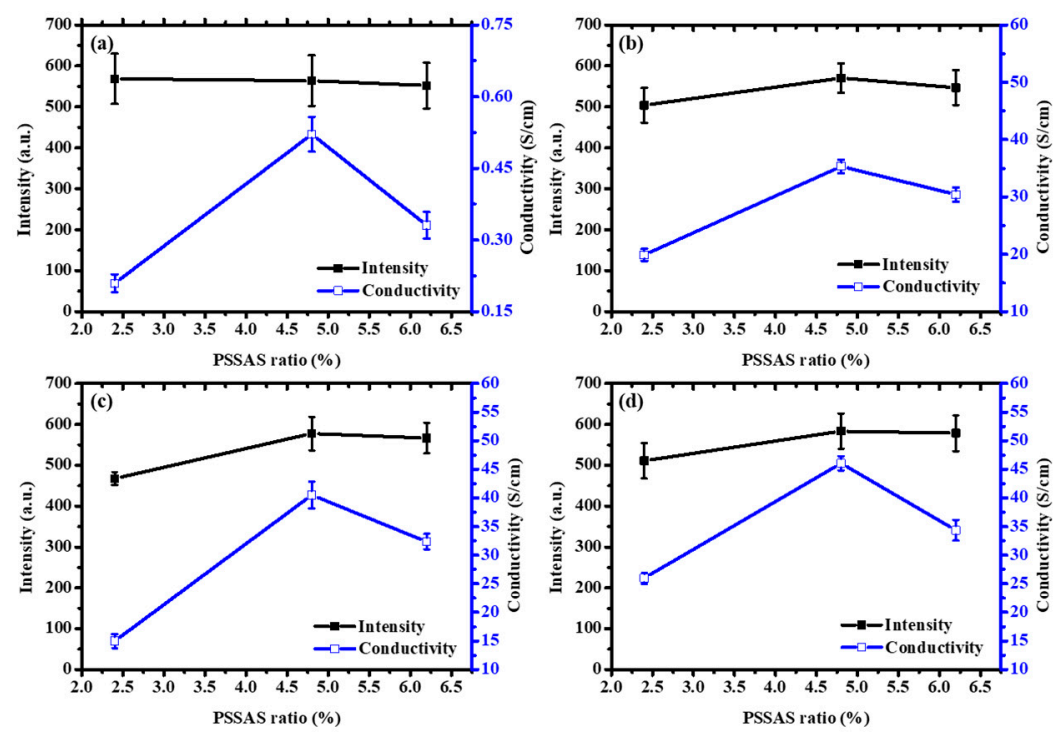

Figure 4. Intensities (black solid square, fitting at $2 \theta=26^{\circ}$ ) and conductivities (blue open square) as functions of PSSAS ratio for PEDOT:PSS thin films with solvent treatments of untreated (a), water/acetone (b), water/ $\mathrm{MeOH}(\mathbf{c})$ and water/EtOH (d).

\section{Conclusions}

In this work, PEDOT:PSS dispersions with various concentrations of PSSAS (2.4, 4.8, and 6.2\%) were synthesized by EDOT in the presence of $200 \mathrm{~mL}$ of water. The PEDOT:PSS films were prepared by spin coating so that the PEDOT:PSS dispersions were dropped onto a substrate. The solventtreated PEDOT:PSS thin films were treated by a solvent of water mixed with acetone (methanol or ethanol) in a ratio of 50:50. In addition, both the organic solvent and water have synergetic effects, which can reduce the dissociation of PSS into PSS anions and protons. This subsequently reduces the Coulombic repulsions among the PSS anions in the same polymer chain. Furthermore, the PSS and PEDOT-attached PSS segments form a coil-like and a linear (or extended-coil) structure, respectively. This may induce the stacking of the linear and planar PEDOT-attached PSS segments, which favors the formation of a crystalline phase. Finally, the best electrical conductivity of the PEDOT:PSS thin films with solvent treatment depends on the best XRD intensity of fitting at $2 \theta=26^{\circ}$ of the film B (4.8\% PSSAS).

Supplementary Materials: The following are available online at http:/ /www.mdpi.com/2073-4360/11/1/134/ www.mdpi.com/xxx/s1. Table S1: Conductivities of the untreated PEDOT:PSS thin film A (2.4\% PSSAS), B (4.8\% PSSAS) and C (6.2\% PSSAS) with an thermal annealing under air atmosphere at $140{ }^{\circ} \mathrm{C}$ for $5 \mathrm{~min}$.

Author Contributions: U.-T.S. and J.-W.S. wrote the manuscript; R.S. assisted to write the manuscript; S.-P.R. and Y.-H.L. conceived the concept and approved the final version of the manuscript.

Funding: This research was funded by the National Science Council of the Republic of China (NSC), Taiwan, for financially supporting this research.

Acknowledgments: The authors would like to thank the National Science Council (NSC) of the Republic of China (NSC), Taiwan and Office of Higher Education Sprout Project.

Conflicts of Interest: The authors declare no conflict of interest.

\section{References}

1. Ha, Y.H.; Nikolov, N.; Pollack, S.K.; Mastrangelo, J.; Martin, B.D.; Shashidhar, R. Towards a transparent, highly conductive poly(3,4-ethylenedioxythiophene). Adv. Funct. Mater. 2004, 14, 615-622. [CrossRef]

2. Crispin, X.; Jakobsson, F.L.E.; Crispin, A.; Grim, P.C.M.; Andersson, P.; Volodin, A.; Haesendonck, C.V.; Auweraer, M.V.D.; Salaneck, W.R.; Berggren, M. The origin of the high conductivity of poly(3,4- 
ethylenedioxythiophene)-poly(styrenesulfonate) (PEDOT-PSS) plastic electrodes. Chem. Mater. 2006, 18, 4354-4360. [CrossRef]

3. Zhang, F.; Johansson, M.; Andersson, M.R.; Hummelen, J.C.; Inganäs, O. Polymer photovoltaic cells with conducting polymer anodes. Adv. Funct. 2002, 14, 662-665. [CrossRef]

4. Pei, Q.; Zuccarello, G.; Ahlskog, M.; Inganäs, O. Electrochromic and highly stable poly(3,4ethylenedioxythiophene) switches between opaque blue-black and transparent sky blue. Polymer 1994, 35, 1347-1351. [CrossRef]

5. Granström, M.; Berggren, M.; Inganäs, O. Micrometer- and nanometer-sized polymeric light-emitting diodes. Science 1995, 267, 1479-1481. [CrossRef]

6. Jonas, F.; Morrison, J.T. 3,4-Polyethylenedioxythiophene (PEDT): Conductive coatings technical applications and properties. Synth. Met. 1997, 85, 1397-1398. [CrossRef]

7. Cao, Y.; Yu, G.; Zhang, C.; Menon, R.; Heeger, A.J. Polymer light-emitting diodes with polyethylene dioxythiophene-polystyrene sulfonate as the transparent anode. Synth. Met. 1997, 87, 171-174. [CrossRef]

8. Heuer, H.W.; Wehrmann, R.; Kirchmeyer, S. Electrochromic window based on conducting poly(3,4ethylenedioxythiophene)-poly(styrene sulfonate). Adv. Funct. Mater. 2002, 12, 89-94. [CrossRef]

9. Kim, T.G.; Ha, S.R.; Choi, H.; Uh, K.; Kundapur, U.; Park, S.; Lee, C.W.; Lee, S.H.; Kim, J.; Kim, J.M. Polymerizable supramolecular approach to highly conductive PEDOT:PSS patterns. ACS Appl. Mater. Interfaces 2017, 9, 19231-19237. [CrossRef]

10. Meng, Q.; Cai, K.; Chen, Y.; Chen, L. Research progress on conducting polymer based supercapacitor electrode materials. Nano Energy 2017, 36, 268-285. [CrossRef]

11. Kirchmeyer, S.; Reuter, K. Scientific importance, properties, and growing applications of poly(3,4ethylenedioxythiophene). J. Mater. Chem. 2005, 15, 2077-2088. [CrossRef]

12. Ouyang, J. "Secondary doping" methods to significantly enhance the conductivity of PEDOT:PSS for its application as transparent electrode of optoelectronic devices. Displays 2013, 34, 423-436. [CrossRef]

13. Shi, H.; Liu, C.C.; Jiang, Q.L.; Xu, J.K. Effective approaches to improve the electrical conductivity of PEDOT:PSS: A review. Adv. Electron. Mater. 2015, 1, 1500017. [CrossRef]

14. Jiang, F.X.; Xu, J.K.; Lu, B.Y.; Xie, Y.; Huang, R.J.; Li, L.F. Thermoelectric performance of poly(3,4ethylenedioxythiophene):poly(styrenesulfonate). Chin. Phys. Lett. 2008, 25, 2202-2205.

15. Liu, C.; Lu, B.; Yan, J.; Xu, J.; Yue, R.; Zhu, Z.; Zhou, S.; Hu, X.; Zhang, Z.; Chen, P. Highly conducting freestanding poly(3,4-ethylenedioxythiophene)/poly(styrenesulfonate) films with improved thermoelectric performances. Synth. Met. 2010, 160, 2481-2485. [CrossRef]

16. Xiong, J.; Jiang, F.; Zhou, W.; Liu, C.; Xu, J. Highly electrical and thermoelectric properties of a PEDOT:PSS thin-film via direct dilution-filtration. RSC Adv. 2015, 5, 60708-60712. [CrossRef]

17. Nardes, A.M.; Kemerink, M.; Kok, M.M.D.; Vinken, E.; Maturova, K.; Janssen, R.A.J. Conductivity, work function, and environmental stability of PEDOT:PSS thin films treated with sorbitol. Org. Electron. 2008, 9, 727-734. [CrossRef]

18. Xia, Y.; Ouyang, J. Anion effect on salt-induced conductivity enhancement of poly(3,4ethylenedioxythiophene):poly(styrenesulfonate) films. Org. Electron. 2010, 11, 1129-1135. [CrossRef]

19. Horii, T.; Hikawa, H.; Katsunuma, M.; Okuzaki, H. Synthesis of highly conductive PEDOT:PSS and correlation with hierarchical structure. Polymer 2018, 140, 33-38. [CrossRef]

20. Xia, Y.; Ouyang, J. PEDOT:PSS films with significantly enhanced conductivities induced by preferential solvation with cosolvents and their application in polymer photovoltaic cells. J. Mater. Chem. 2011, 21, 4927-4936. [CrossRef]

21. Aasmundtveit, K.E.; Samuelsent, E.J.; Pettersson, L.A.A.; Inganäs, O.; Johansson, T.; Feidenhans, R. Structure of thin films of poly(3,4-ethylenedioxythiophene). Synth. Met. 1999, 101, 561-564. [CrossRef]

22. Niu, L.; Kvarnström, C.; Fröberg, K.; Ivaska, A. Electrochemically controlled surface morphology and crystallinity in poly(3,4-ethylenedioxythiophene) films. Synth. Met. 2001, 122, 425-429. [CrossRef]

23. Kim, E.G.; Brédas, J.L. Electronic evolution of poly(3,4-ethylenedioxythiophene) (PEDOT): From the isolated chain to the pristine and heavily doped crystals. J. Am. Chem. Soc. 2008, 130, 16880-16889. [CrossRef] [PubMed]

24. Kim, J.Y.; Jung, J.H.; Lee, D.E.; Joo, J. Enhancement of electrical conductivity of poly(3,4ethylenedioxythiophene)/poly(4-styrenesulfonate) by a change of solvents. Synth. Met. 2002, 126, 311-316. [CrossRef] 
25. Ouyang, J.; Xu, Q.; Chu, C.W.; Yang, Y.; Li, G.; Shinar, J. On the mechanism of conductivity enhancement in poly(3,4-ethylenedioxythiophene):poly(styrene sulfonate) film through solvent treatment. Polymer 2004, 45, 8443-8450. [CrossRef]

26. Lee, S. Conductivity enhancement of PEDOT:PSS films through the surface treatment with organic solvent. J. Nanosci. Nanotechnol. 2016, 16, 2880-2882. [CrossRef]

27. Hsiao, Y.S.; Whang, W.T.; Chen, C.P.; Chen, Y.-C. High-conductivity poly(3,4-ethylenedioxythiophene): poly(styrene sulfonate) film for use in ITO-free polymer solar cells. J. Mater. Chem. 2008, 18, 5948-5955. [CrossRef]

28. Yasud, M. Dissociation constants of some carboxylic acids in mixed aqueous solvents. Bull. Chem. Soc. Jpn. 1959, 32, 429-432. [CrossRef]

29. Barrón, D.; Butí, S.; Ruiz, M.; Barbosa, J. Evaluation of acidity constants and preferential solvation in tetrahydrofuran-water mixtures. Polyhedron 1999, 18, 3281-3288. [CrossRef]

30. Takano, T.; Masunaga, H.; Fujiwara, A.; Okuzaki, H.; Sasaki, T. PEDOT nanocrystal in highly conductive PEDOT:PSS polymer films. Macromolecules 2012, 45, 3859-3865. [CrossRef]

(C) 2019 by the authors. Licensee MDPI, Basel, Switzerland. This article is an open access article distributed under the terms and conditions of the Creative Commons Attribution (CC BY) license (http:// creativecommons.org/licenses/by/4.0/). 